\section{PELO TEMPO E CONTRA O TEMPO: O PARADOXO DAS ATLETAS PARALÍMPICAS COM DOENÇAS DEGENERATIVAS}

\author{
FOR TIME AND AGAINST TIME: THE PARADOX OF PARALYMPIC \\ ATHLETES WITH DEGENERATIVE DISEASES C
}

POR EL TIEMPO Y CONTRA EL TIEMPO: LA PARADOJA DE LAS

ATLETAS PARALIMPICAS CON ENFERMEDADES DEGENERATIVAS C

doi) https://doi.org/10.22456/1982-8918.100207

Luciane Maria Micheletti Tonon*<luciane.tonon@usp.br>

Katia Rubio*<katrubio@usp.br>

*Universidade de São Paulo. São Paulo, SP, Brasil.
Resumo: Este ensaio visa compreender como as atletas paralímpicas com doenças degenerativas Susana Schnarndorf, da natação, e Elizabeth Gomes, do atletismo, lidam com a dicotomia do tempo que o esporte Ihes confere. Uma luta "contra" o relógio para conquistas de índices e a "favor" da extensão do tempo de vida. Paradoxalmente, traz falas da velocista belga Marieke Vervoort, que preferiu romper com o tempo de vida e das competições. A metodologia usada são as narrativas biográficas, que partem de um convite para que as atletas contem suas histórias de vida. Resultam das narrativas elementos de subjetividade, que lidam não apenas com o papel social dessas mulheres como atletas, mas como seres humanos, que sofrem com a condição da mortalidade e de uma finitude breve, marcada pela doença. A aproximação com personagens literários é uma forma de metaforizar a aspereza desse vislumbre tão tênue entre a finitude e a eternidade.

Palavras chave: Traumatismos em Atletas. Pessoas com Deficiência. Doença Crônica. Paratletas.
Recebido em: 05-02-2020 Aprovado em: 08-12-2020 Publicado em: 29-12-2020

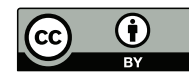

Este é um artigo publicado sob a licença Creative Commons Atribuição 4.0 Internacional (CC BY 4.0). eISSN: $1982-8918$ 


\section{INTRODUÇÃO}

O tempo no sentido amplo da palavra nos remete a inúmeros temas, como vida, morte, calendário, espaço, entre outros, fazendo-se presente em enredos de filmes, livros ou poesias. Hartog (2003) ressalta que existem vários momentos em que o tempo foi objeto de reflexões, de especulação, medos e sonhos.

Quando trazemos o tempo na zona semântica do esporte, encontramos o relógio como objeto de grande valia, uma vez que a luta de atletas de alto rendimento é justamente contra essa máquina de registrar a duração do tempo. Logicamente, o tempo no sentido evocado por Elias (1998) sobre algo perfeitamente passível de ser captado, como os minutos e os segundos. Processo que vamos chamar de luta "contra o tempo".

Porém, ao analisarmos o tempo desenvolvido de maneira inexorável, invisível, não palpável, como anuncia Tarde (1901), é possível entender uma dimensão temporal não medida por relógios ou calendários, como explicam alguns autores. Ainda que o tempo seja linear, Rubio (2014) afirma que ao nascer o sujeito traça uma linha e por ela segue até chegar à morte. Mesma perspectiva de continuidade, tem-se também a concepção daquele tempo que parece nunca se esgotar, transformandose à medida que se reveste de significado. Do ponto de vista de Bachelard (1988), o tempo pensado é tempo vivido em estado nascente. O pensamento é sempre em alguns aspectos, a tentativa ou o esboço de uma vida nova, uma tentativa de viver de outro modo, de viver mais ou, até mesmo, uma vontade de ultrapassar a vida. Já Montaigne (2002), no Livro I de seus Ensaios, diz que o tempo tudo desestabiliza. Ou seja, mesmo os planos mais perfeitamente elaborados serão transformados pelo passar do tempo.

Nesse sentido, a dimensão temporal não pode ser resumida a instrumentos contabilizadores. O tempo nos ensina através de sua instantaneidade. De repente o que era não é mais; e o que não era passa a ser. Assim, Bachelard (2002) diz que há a necessidade de se aprender e reaprender nossa própria cronologia.

Aprendizagem essa bastante assimilada pelas protagonistas deste estudo, as atletas paralímpicas Susana Schnarndorf (natação) e Elizabeth Gomes (atletismo). Ambas têm doenças neurodegenerativas progressivas, que afetam o sistema nervoso e acarretam a paralisia motora irreversível, de maneira limitante (MINISTÉRIO DA SAÚDE, 2018). Tal diagnóstico literalmente disparou o cronômetro da vida dessas atletas, que passaram a viver a dicotomia "pelo tempo" e "contra o tempo", já que disputam contra o relógio nas competições. E lutam a favor de que o tempo de suas vidas se prolongue, tendo o esporte e os treinos diários como o melhor remédio.

Após serem diagnosticadas, as atletas tiveram duas opções: parar no tempo e esperar o fim, ou fazer do tempo o maior aliado para se eternizarem no esporte. Tais respostas foram destacadas em seus discursos e apoiadas em algumas frases do filósofo francês Gaston Bachelard (1988), quando escreve sobre $A$ dialética da duração, ou em $A$ intuição do Instante (2002a, 2010 b). Já o paradoxo de tais discursos sobre a extensão ou não do tempo parte da posição da atleta belga Marieke Vervoort, que decidiu findar seu tempo no cronômetro das pistas e na vida, saindo 
de cena em seu melhor momento no esporte. Assim sendo, o objetivo deste ensaio é compreender como as atletas Elizabeth Gomes e Susana Schnarndorf lidam com essa dicotomia da extensão do tempo na continuidade da vida e o encurtar do tempo na conquista de índices e marcas, subentendendo literalmente uma luta pelo tempo e contra o tempo.

\section{METODOLOGIA}

O método empregado são as narrativas biográficas (RUBIO, 2014) que se estendem para além de marcos históricos ou sociais e adentra o campo da subjetividade marcado por construções simbólicas que devem ser entendidas nesse contexto. "São discursos individuais que oferecem uma compreensão do sujeito que narra, do mundo e das próprias experiências acumuladas na trajetória da existência" (RUBIO, 2014 p.115). Narrativas são entendidas por Benjamin (2012) como forma artesã de comunicação e permitem, segundo Rubio (2014, p.112):

[...] a reexperimentação de situações passadas não apenas do ponto de vista do desenrolar dos fatos, mas pela ressignificação de episódios marcantes para o narrador, que se permite inverter ou subverter a narração obedecendo a uma cronologia própria a afetividade implicada no evento ocorrido, dando ao seu texto, um contexto.

O termo "biográficas" é porque considera "os dados relevantes da trajetória do narrador dando uma ideia do que foi sua vida e do que ele mesmo é nesse momento" (RUBIO, 2014, p. 112).

Para este estudo, as narrativas foram gravadas em encontros presenciais tanto nos ambientes de competições como fora deles. A partir do convite às atletas para que contassem suas histórias de vida, abriu-se um processo dialógico entre elas e a pesquisadora. A metodologia tem como princípio evitar perguntas diretivas, deixando o tempo livre para as falas e respeitando o silêncio, caso expressados. Leão (2016, p.27) diz que para isso é preciso se abrir para a percepção atenta, renunciando a qualquer opinião antecipada, preconceito ou juízo de valor. "Precisamos mergulhar na percepção atenta com uma postura que evita julgamentos afobados".

Com o material bruto nas mãos, foram feitos alguns recortes de quando as atletas se referiam ao tempo. Depois de transcritas, as falas em destaque foram apoiadas no discurso poético do filósofo Gaston Bachelard ou ainda em trechos literários como de Gabriel García Márquez e Fernando Pessoa para metaforizar e minimizar a dureza deste enredo dicotômico que vivem as atletas. Algumas frases também foram tiradas de entrevistas concedidas para a mídia ou em postagens nas redes sociais das atletas. As falas da atleta belga Marieke Vervoort foram gravadas durante uma entrevista coletiva concedida durante os Jogos Paralímpicos Rio, 2016. Também foi possível presenciar o encontro dela com a nadadora Susana Schnarndorf, no mesmo evento.

Uma das aprendizagens durante os encontros foi que ao ouvir atletas paralímpicos é preciso deixar de lado as concepções de que são "super-humanos", como tratados algumas vezes pela imprensa em geral, e entender que são pessoas comuns, sujeitas às intempéries da vida como qualquer um, com suas virtudes e 
fraqueza, grandezas e limitações. Para isso Lima (2009) aconselha que é preciso lançar um olhar de identificação e projeção humana da nossa própria condição nos nossos semelhantes, sejam eles celebridades ou pessoas do cotidiano.

Esse estudo faz parte da pesquisa: Olímpicos e Paralímpicos: separados por um instante, desenvolvida na Escola de Educação Física e Esportes da USP, sob financiamento da Coordenação de Aperfeiçoamento de Pessoal de Nível Superior (Capes) e está vinculada à pesquisa Memórias Olímpicas por Atletas Olímpicos Brasileiros, aprovada pelo Comitê de Ética da Escola de Educação Física da Universidade de São Paulo no processo 0052.0.342.000-09. As atletas Elizabeth Gomes e Susana Schnarndorf foram entrevistadas para a pesquisa e assinaram um termo de consentimento livre e esclarecido, autorizando o uso dos dados na pesquisa científica. A atleta Marieke concedeu entrevista coletiva para imprensa, onde estivemos presentes.

\section{CONTRA O TEMPO}

Ao entrar todos os dias na piscina, mentaliza seu único foco: diminuir seu tempo, tomado diariamente pelas batidas do cronômetro. Quanto menor, mais feliz se sente. É assim a rotina de Susana Schnarndorf, nadadora paralímpica, que antes foi uma triatleta somando em seu currículo 13 Ironman - prova que compila $3,8 \mathrm{~km}$ de natação, $180 \mathrm{~km}$ de ciclismo e 42,195 km de corrida. Representou o Brasil nos Jogos Pan-americanos de Mar Del Plata, em 1995. Porém, sua carreira olímpica foi interrompida em 2005, com uma forte depressão após o nascimento de sua terceira filha e a separação matrimonial. Tal quadro acarretou uma doença degenerativa chamada Síndrome da Atrofia Múltipla - SMA, doença próxima ao Parkinson, que vai paralisando os músculos aos poucos. Desde então, sua corrida de longa distância passou a ser a favor da própria vida. Foram cinco anos na busca de tratamentos.

A piora do quadro de saúde levou à sua maior derrota, perder a guarda dos filhos. Pensou ser o fim de tudo. Em 2010, porém, foi apresentada para a natação paralímpica. Relutou achando-se velha, já com 40 anos na época. Mas voltar a competir lhe gerou a sensação de poder reviver, de se aceitar e de minimizar seu próprio sofrimento. A convite da equipe brasileira, foi ao Canadá fazer sua classificação funcional - processo que qualifica o atleta para pertencer a uma determinada classe conforme suas limitações motoras, visuais ou intelectuais, podendo, assim, competir em condições de igualdade (INTERNATIONAL PARALYMPIC COMMITTEE, 2015). Venceu sua primeira competição e bateu cinco recordes brasileiros, classificada como S8 - S em inglês - Swimm e 8 significa nível de baixo comprometimento físico, já que a escala é retrocedente de S14 a S1. SB8: é nado peito; SM8 - medley e S8 crawl, costas e borboleta.

Susana reencontrou a alegria no tempo palpável, que o tempo inexorável tentara lhe tirar. Assumiu a profissão de atleta paralímpica e já em 2012 representou o Brasil nos Jogos Paralímpicos de Londres, conquistando o quarto lugar na prova de 50 metros, estilo peito. Usando o tempo de vida a seu favor, diminuiu seu tempo na piscina e em 2013, conquistou o título de campeã mundial de nado peito, classe S6 - 
grau de comprometimento moderado, devido ao avanço da doença - deixando ínfimo o tempo cronometrado. Tal conquista fez com que Susana fosse eleita a Melhor Atleta do Ano, prêmio concedido pelo Comitê Paralímpico Brasileiro (CPB). Aqui o menor e o maior tempo se abraçaram e a levaram mais longe. $O$ ápice de sua carreira foi ser medalhista de prata nos Jogos Paralímpicos, Rio 2016, na classe S5. Destaca-se mais uma vez a queda de classe, pela progressão da síndrome.

Estava brincando com as meninas de classe mais baixa [S4, S3]: 'Se liga, que estou chegando'. Conforme minha doença progride vou mudando de classe e me adequando, mas até hoje eu sinto agonia, eu não nado como eu nadava antes, então tenho que saber o que eu consigo fazer agora e tentar nadar de outro jeito. Preciso fazer isso quase que diariamente (SCHNARNDORF, 12/10/2015).

Já a arremessadora de peso paralímpica Elizabeth Gomes compete contra o tempo dos surtos e sequelas que sua doença pode causar. Começou a jogar voleibol aos 14 anos representando a cidade de Santos/SP em campeonatos escolares e na maioridade se engajou na Guarda Municipal, disputando pela classe. Foi tricampeã santista. Em 1993, enquanto se dirigia ao Batalhão onde trabalhava, sofreu uma queda e fraturou a tíbia. Logo veio a saber que era a primeira manifestação da Esclerose Múltipla - doença que afeta o sistema nervoso de forma degenerativa e progressiva e acarreta paralisia motora irreversível (BRASIL, Ministério da Saúde, 2018). Em plena forma, com 23 anos, Elizabeth entrou em depressão por não aceitar a interrupção de sua carreira de atleta. Foram dois anos na busca de tratamentos e respostas ao seu "futuro traído", como menciona Bachelard:

Como o luto mais cruel é a consciência do futuro traído e, quando sobrevém o instante lancinante em que um ente querido fecha os olhos imediatamente se sente como que novidade hostil, o instante seguinte assalta nosso coração (BACHELARD, 2002, p. 19).

Até que em junho de 1996 lhe apresentaram o basquete sobre rodas. "Me chamaram para jogar e num primeiro momento recusei, mas depois pensei e fui ver o que era [...] foi dentro da mesma quadra onde tinha sido tricampeã de voleibol da polícia civil. Isso mexeu muito comigo" (GOMES, 11/09/2019).

Beth Gomes, como é conhecida, começou a treinar na Associação dos Deficientes Físicos de Santos (ADFISA). "Ali, o professor chamado Augusto me colocou na cadeira, me deu uma bola na mão e falou: 'Cai pra quadra'” (GOMES, 11/09/2019). Mostrando habilidades com a bola não tardou para ser titular do time no campeonato santista, que aconteceu em outubro do mesmo ano. Destacou-se e foi contratada pela equipe Leite Moça dos Hospital das Clínicas em São Paulo. Na sequência foi convocada para a seleção brasileira, dando início oficialmente à sua carreira de atleta paralímpica. Foi para os Jogos de Pequim em 2008 e representou o país até 2010. Sua doença progredira e o tempo inexorável estava se sobrepondo ao tempo palpável, como enfoca Tarde (1901), a dimensão temporal perde o sentido não discute presente/passado ou futuro. É ser ou não ser.

Sentiu ser a hora de parar com o basquete, mas não parar de ser atleta. Como paralelamente já vinha se aventurando em corridas de cadeiras de rodas, resolveu migrar para o atletismo. Venceu os cronômetros se consagrando hexa campeã da 
prova 10 quilômetros da Tribuna de Santos e algumas provas de pistas. Porém, a esclerose estava no páreo, tomando seu tempo de vida e provocando mais sequelas. Beth, então, deixou as pistas e foi para as provas de campo. No arremesso de peso, lançamento de dardo e disco viu que conseguiria continuar sua carreira. Pelo seu desempenho, em 2011 foi convocada para o Parapan de Guadalajara e ficou em $5^{\circ}$ lugar do mundo.

Meu primeiro Parapan-americanos. Estava feliz, minha continuidade de vida se deu por querer viver de uma forma melhor. O esporte me fez renascer, porque minha vidar era o esporte. Faço possível para a esclerose não se tornar minha aliada, ela é só minha colega, ela vive do meu lado, caminha do meu lado, mas ela jamais vai me vencer. Eu sempre estou vencendo a cada dia, a cada surto, a cada sequela (GOMES, 11/09/2019).

Por conta de a deficiência de Beth ser progressiva e não estável como as de atletas amputados, por exemplo, ela deve ser reclassificada a cada dois anos. Iniciou nas modalidades de campo sendo da classe F54 - (F - "Field") e (54) categoria de cadeirantes, que varia de 51 a 57 - sendo respectivamente do maior ao menor grau de comprometimento (INTERNATIONAL PARALYMPIC COMMITTEE, 2015, online). Nessa classe, consagrou-se campeã Parapan-americana; Sul-americana; Brasileira e segunda colocada no ranking mundial.

No entanto, viveu seu maior infortúnio em abril de 2016. Ao passar pelo processo de reclassificação durante o Open Internacional de Atletismo em São Paulo, foi surpreendida por um resultado adverso, praticamente às vésperas dos Jogos Paralímpicos. Mesmo estando com suas habilidades mais comprometidas do que há dois anos, a equipe de classificadores considerou haver tônus na musculatura do braço, o que, na verdade, segundo a atleta, era uma contratura espasmódica e não força muscular (TONON, 2017). Assim, a subiram para a classe F55, em que o arremesso de peso não entraria nos Jogos por falta de competidoras. Ou seja, Beth não pôde realizar seu grande sonho, que era competir nos Jogos Rio 2016.

\section{PELO TEMPO}

O tempo palpável passou e o inexorável trouxe às atletas outras surpresas. Apesar de a luta de Susana nas piscinas ser contra o tempo, sua principal fala é a favor dele, deixando muito claro que a razão para recomeçar a carreira de atleta foram os filhos: "Nado pelos meus filhos, para que meus dias se prolonguem na terra", (SCHNARNDORF, 12/10/2015). Isso porque há 15 anos a natação tem sido o melhor remédio para a convivência com a doença. Recorrendo a Bachelard (1988 p.76), ele enfatiza: "O que permanece? Apenas aquilo que tem razões para recomeçar".

Elizabeth, mesmo tendo novamente seu "futuro traído", ressalta o valor do tempo: "O tempo me faz crescer e acreditar que em algum momento da minha vida, diante do que aconteça o tempo me trará as respostas [...] É uma questão de aprendizado" (GOMES, 11/09/2019). No mesmo viés, Bachelard nos faz entender:

Se nosso coração fosse amplo o bastante para amar a vida em seus pormenores, veríamos que todos os instantes são a um tempo doadores e espoliadores e que uma novidade recente ou trágica, sempre repentina não cessa de ilustrar a descontinuidade essencial do tempo (BACHELARD, 2010, p.18). 
Em abril de 2018, as duas passaram por uma nova reclassificação funcional que as fez cair para classes de bastante comprometimento físico, Susana para a S4 e Beth para F52. Isso significa avanço nas respectivas doenças, mas no âmbito de competição é sempre um recomeço. Em suas redes sociais, coincidentemente na mesma competição, as duas postaram expressões de alegria por novas conquistas. Na Figura 1 a atleta Elizabeth Gomes está lançando o disco apoiada na barra de segurança, durante o Open Internacional de Atletismo em São Paulo.

Figura 1 - Elizabeth Gomes

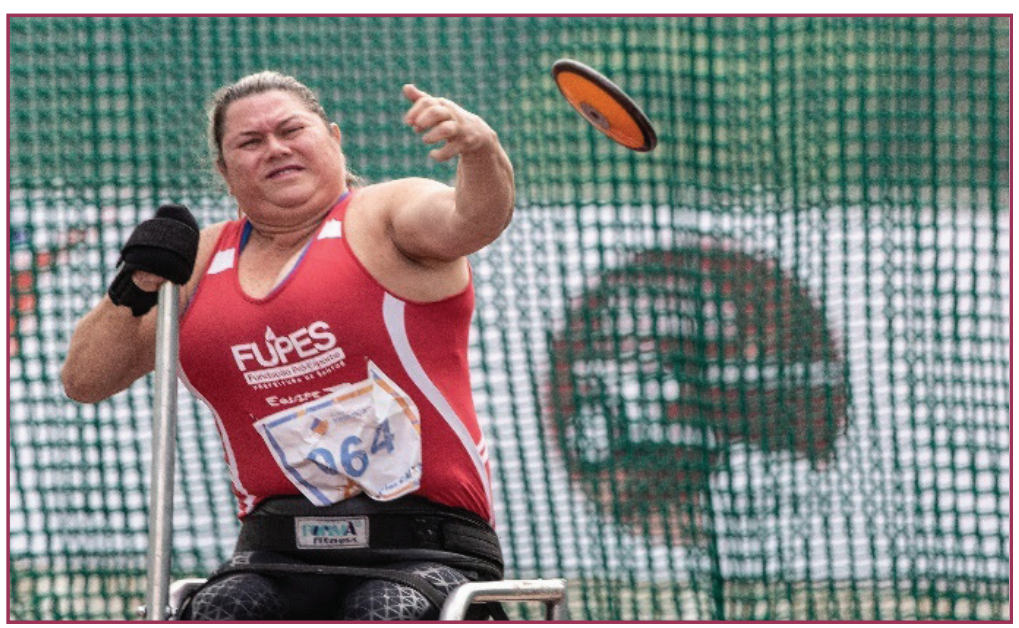

Fonte: Foto concedida por Daniel Zappe/CPB/MPIX

Hoje minha estreia no Open Internacional foi um novo recomeço com recordes das Américas e com índice A. Obrigada a todos que torceram por mim e este Recorde dedico em especial a minha coach, Rose - gratidão é a palavra que sempre terei por você (GOMES, 2018, online)

A Figura 2 mostra Susana Schnarndorf durante treinamentos preparatórios para o Open Internacional de natação em São Paulo.

Figura 2 - Susana Schnarndorf

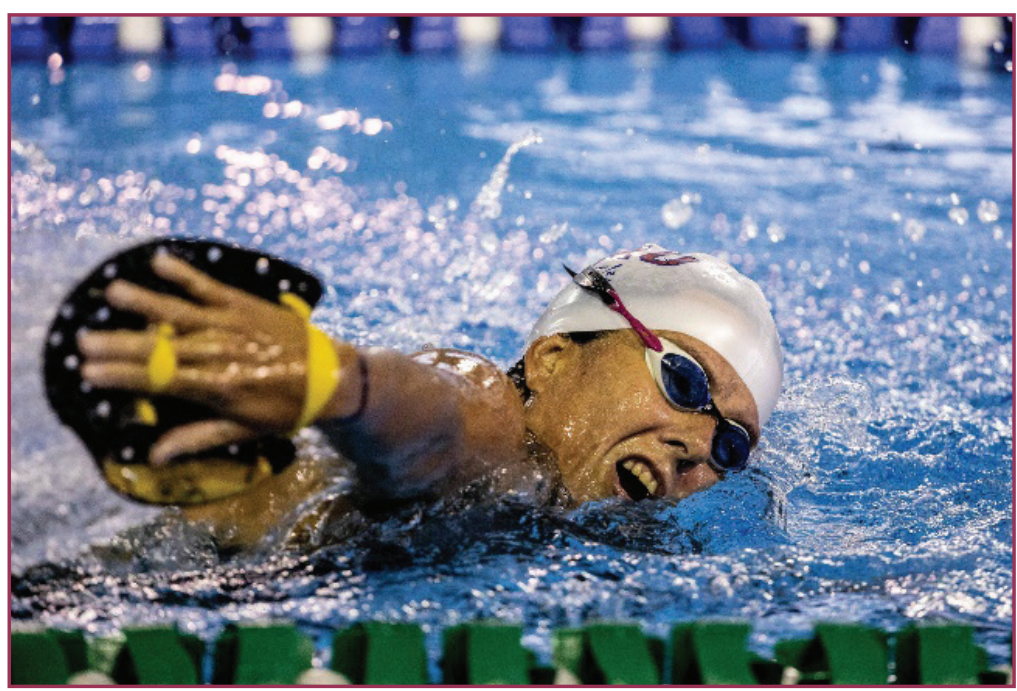

Fonte: Foto concedida por Daniel Zappe CPB/MPIX

Sobre o segundo dia do Open... Depois de tempos difíceis, entre aspas, nadei hoje os 150 medley na minha nova classe, S4 e bati o recorde 
brasileiro da prova. Feliz demais. O caminho às vezes fica difícil, outras vezes fica muito difícil. Mas, o importante é seguir sempre em frente com muita fé (SCHNARNDORF 27/04/2018 Facebook pessoal da atleta).

\section{DISCUSSÃO: FINITUDE X ETERNIDADE}

O dicionário nos apresenta a finitude como particularidade ou condição do que é finito. Difícil é pensar no termo como a oportunidade de dar sentido à vida, ainda mais por ser um assunto que o ser humano faz questão de manter longe de si. Segundo Ribeiro (2008), tal fato se relaciona à dificuldade que o ser humano encontra em lidar com o desconhecido; por isso o pavor e a recusa diante do fato de perder pessoas queridas. Kübler-Ross (2015) acredita que o maior obstáculo a ser enfrentado quando se procura compreender a morte é o fato de que é impossível para as pessoas imaginarem um fim para a sua própria vida.

Mas a morte pode nos ser apresentada com hora marcada, como no caso de Susana, que durante a busca pelo seu diagnóstico teve a morte anunciada várias vezes: "Já me mandaram morrer umas cinco vezes", (SCHNARNDORF, 12/10/2015). Então sim, para ela esse foi o momento de rechear a vida que lhe resta de plenos sentidos e usar a piscina como sua melhor terapia. A história da nadadora faz lembrar a Crônica de uma Morte Anunciada, de Gabriel García Márquez (1981), que narra a história de Santiago Nasar, um jovem de 21 anos que estava jurado de morte e todos os relatos da trajetória do personagem no dia da sua suposta morte partem dos próprios moradores da cidadezinha onde viviam. "O dia em que iam matá-lo, Santiago Nasar se levantou às $5 \mathrm{~h} 30$ da manhã para esperar o navio que chegaria" (MÁRQUEZ, 1981, p.9). Muitos dos que estavam no porto sabiam que iam matá-lo, mas ninguém sequer perguntou se ele estava prevenido. Era possível ouvir vários comentários: "Não é justo que todo mundo saiba que vão matá-lo e que ele seja o único a não saber" (MÁRQUEZ, 1981, p.40). "Eu tinha mil razões muito reais para crer que já não corria mais perigo" (Márquez, 1981, p.35). "Nunca houve uma morte mais anunciada" (MÁRQUEZ, 1981, p.83). Susana não estava prevenida para morrer, foi pega de surpresa ao ouvir diagnósticos que anunciavam seu fim, como: "há suspeitas de um tumor cerebral", ou "vamos investigar se é lúpus", entre outros. Por vezes aceitou o findar de sua jornada a ponto de entregar a guarda dos três filhos ao ex-marido. Mas ela ainda não tinha eternizado sua identidade de atleta e, por isso, continuou a nadar.

A finitude também deu mais um "olé" na vida de Elizabeth Gomes no final de 2017, com um surto da esclerose que prejudicou ainda mais seus movimentos. No entanto, a história a chamou para deixar a sua marca. Em 2018 ela bateu três recordes mundiais. No arremesso de peso, estabeleceu a marca 7,41m. O antigo recorde pertencia à americana Cassie Mitchell, com 6,14m. Na prova de lançamento de disco, com 16,44m, Beth bateu a marca da tcheca Martina Kniezkova, 15,28m, recorde mundial desde os Jogos de Atenas, 2004. Nova oportunidade e novo recorde, dessa vez registrado no Grand Prix de Paris, na França, lançou 16,81m, superando seu próprio recorde de $16,44 \mathrm{~m}$. Na sequência em Berlim na Alemanha ela quebrou o recorde do lançamento de dardo com a marca de 14,16 metros. "É uma experiência 
nova, o recorde mundial escreve meu nome na história do esporte paralímpico, é uma sensação absurdamente diferente [...] Mesmo aos 53 anos continuo evoluindo" (PREFEITURA DE SANTOS, 2018, online).

A atleta não parou por aí. Mesmo tendo as duas mãos em garra, pela atrofia da esclerose, em 2019 foi campeã no lançamento de disco nos Jogos ParapanAmericanos de Lima e no Mundial de Paratletismo em Dubai, onde bateu o recorde mundial da prova pela terceira vez consecutiva. Tais feitos também lhe renderam o prêmio do CPB de Melhor Atleta Paralímpica do ano.

As campeãs do tempo continuam nas disputas a favor e contra ele. Mas o paradoxo real da finitude versus eternidade foi designado para a atleta belga Marieke Vervoort, que após se eternizar no Movimento Paralímpico ganhando ouro e prata nos 100 e 200 metros dos Jogos de Londres 2012, bronze e prata nos 100 e 400 metros dos Jogos Rio 2016, decidiu pela finitude ao ter em mãos o direito da eutanásia $^{12}$. A atleta era vítima de uma tetraplegia progressiva, que afeta as quatro extremidades, bem como a musculatura do tronco, causando impossibilidade de mover os membros, em grau variável; além de distúrbios da mecânica respiratória, podendo causar demência leve (PINHEIRO et al., 2011). Sua maior adversária não era a deficiência em si, pois desde os 20 anos estava numa cadeira de rodas, mas as dores insuportáveis. A atleta declarou em uma entrevista para o jornal El País: "Dores estúpidas. Você conhece alguém que precise de morfina para treinar?" (SANCHÉZ, 2016, online).

A Bélgica tem a lei promulgada a favor da eutanásia desde 2002. Em 2014, Marieke obteve do governo o direito de findar as dores quando não achasse mais que valesse a pena continuar. Sentia-se realizada e estava no ápice de sua carreira, como deixou claro em suas redes sociais dias antes da sua morte, que ocorreu em 23 de outubro de 2019: "Vivi coisas com as quais a maioria das pessoas só pode sonhar".

Durante os Jogos Rio 2016, a nadadora Susana Schnarndorf fez questão de se encontrar com Marieke para tentar fazê-la mudar de ideia e sugerir que se encontrassem em Tóquio 2020 (na ocasião, os Jogos ainda não haviam sido adiados). Observamos o diálogo sem interferir. No mesmo dia, Marieke se pronunciou em uma entrevista coletiva, enfatizando como gostaria de ser eternizada:

[...] Esta medalha tem dois lados: de um lado a felicidade, do outro a dor e o adeus [...] Quero ser lembrada como a moça que sempre sorria, que mesmo sofrendo tentou ver o que há de melhor [...] Já fiz uma lista de desejos, como voar num caça, criar um museu e contar a minha história em palestras. A eutanásia é uma escolha que me deu paz e queria que se abrisse um grande debate sobre o tema [...] Preciso abandonar o esporte, porque a doença está piorando. Está ficando mais difícil participar de corridas do que há quatro anos [...] Foi um processo longo, diferentes médicos e psiquiatras precisaram atestar que eu não queria me suicidar, que realmente eu tenho algo incurável e que nunca vou melhorar dessas condições, só piorar (VERVOORT, 11/09/2016) ${ }^{3}$.

\footnotetext{
1 Eutanásia é o ato intencional de proporcionar a alguém uma morte indolor para aliviar o sofrimento causado por uma doença incurável ou dolorosa (AUGUSTYN, 2019).

2 A eutanásia, propriamente dita, é a promoção do óbito. É a conduta, através da ação ou omissão do médico, que emprega, ou omite, meio eficiente para produzir a morte em paciente incurável e em estado de grave sofrimento, diferente do curso natural, abreviando-lhe a vida (SÁ, 2001).

3 Informação verbal concedida em entrevista coletiva nos Jogos Paralímpicos do Rio, 2016.
} 
Corroborando seu discurso sem a audácia de analisá-lo, cito Bachelard quando diz: "Foi na alegria e não na dor, que o homem encontrou o seu espírito" (BACHELARD, 2008 p. 39). O que Marieke tentava todos os dias era achar a melhor forma de lidar com a dor, e ter a licença da eutanásia nas mãos lhe trazia um conforto. Ainda sobre os Jogos Rio, 2016, em sua última postagem a atleta escreveu: "Não podemos esquecer as boas lembranças" (VERVOORT, postagem em Instagram 18/09/2019 - tradução nossa). Na Figura 3 a atleta Marieke Vervoort está em volta de aquecimento.

Figura 3 - Vervoort durante os Jogos Rio, 2016

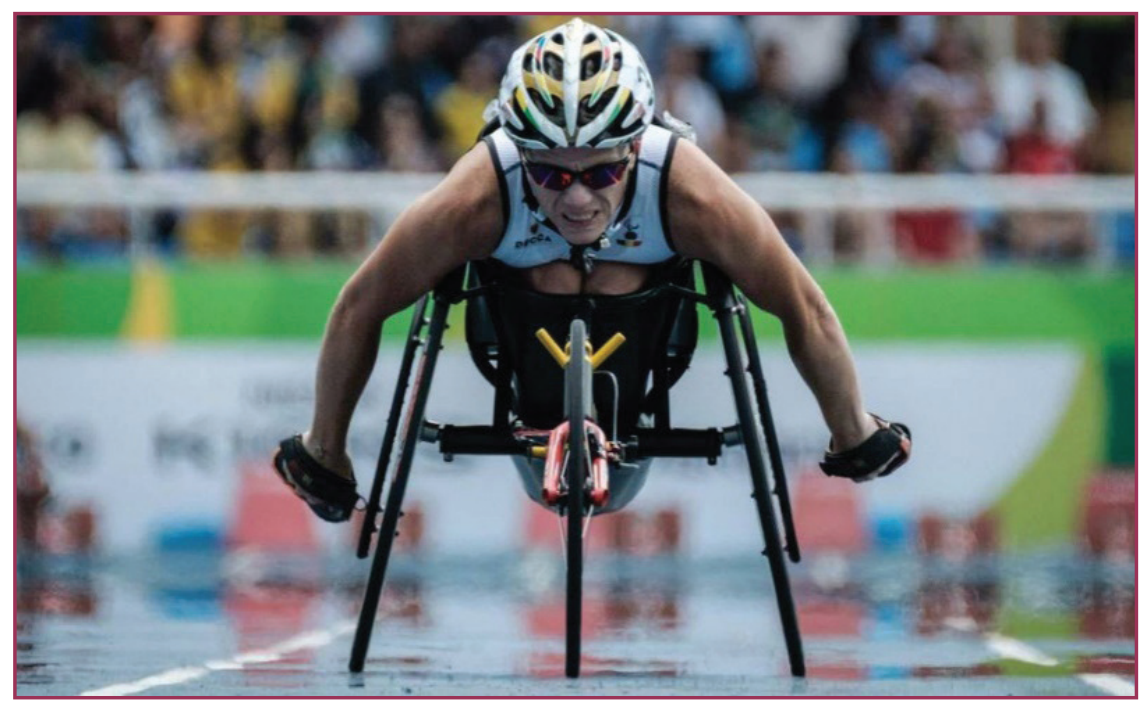

Fonte: Foto pública de YASUYOSHI CHIBA (AFP)

\section{CONSIDERAÇÕES FINAIS}

Resultam das narrativas elementos de subjetividade que lidam não apenas com o papel social dessas mulheres como atletas, mas como seres humanos, que sofrem com a condição da mortalidade e de uma finitude breve, marcada pela doença. A aproximação com personagens literários é uma forma de metaforizar a aspereza desse vislumbre tão tênue entre a finitude e a eternidade.

Ao escolherem o esporte como o maior estímulo da pouca vida que ainda têm, as atletas ressignificaram o tempo, pois as marcas conseguidas perpetuam ambas na história, ainda que a vida seja breve. Como ressalta Rubio (2001, p. 216):

Ser atleta é alvo de projeção de grande parcela da população. Reside na possibilidade de realizações semelhantes e na consequente permanência, a esperança de um futuro que inscreva seu nome na história, como tiveram os heróis-atletas da Antiguidade.

Elas aceitaram a oportunidade de saltar da finitude para a eternidade. A eternidade, por sua vez, é o infinito. O termo costuma ser entendido em dois sentidos. No sentido comum, significa "sempiternidade" (do latim sempiternus, a, um: "perpétuo, eterno, imortal"), isto é, duração ou tempo infinito. No sentido inexorável, corresponde à atemporalidade, ou seja, transcende o próprio tempo. Firma-se, então, o fundamento de Bachelard (2002) quando enfatiza que nessa ruptura do ser a ideia do descontínuo se impõe de forma incontestável sem a menor sombra de dúvida. 
Portanto, se a hora do relógio é precisa, para as atletas que colaboraram com este artigo, o tempo de vida, não. Parafraseando o general romano Pompeu 106-48 a.C., "Navegar é preciso, viver não é preciso"” (PLUTARCO, 2010, Tomo V), referindo-se aos marinheiros amedrontados que recusavam viajar durante a guerra e muito usada pelo poeta português Fernando Pessoa: "Viver não é necessário; o que é necessário é criar" (SANTISI, 2003, online). No caso dessas atletas podemos dizer: Viver não é preciso, competir é.

\section{REFERÊNCIAS}

AUGUSTYN, Adam (Ed.). Euthanasia. The Editors of Encyclopedia Britannica. Disponível em: https://www.britannica.com/topic/euthanasia.2019. Acesso em: 04 dez. 2019.

BACHELARD, Gaston. A Dialética da Duração. São Paulo, Ática, 1988.

BACHELARD, Gaston. A intuição do instante. Campinas: Verus, 2002.

BACHELARD, Gaston. A poética do espaço. São Paulo: Martins Fontes, 2008.

BACHELARD, Gaston. A intuição do instante. 2. ed. Campinas: Versus, 2010.

BENJAMIN, Walter. Obras escolhidas: São Paulo: Brasiliense, 2012.

BENJAMIN, Walter. Obras escolhidas. (V1) São Paulo: Brasiliense, 2012.

ELIAS, Norbert. Sobre o tempo. Rio de Janeiro: Zahar, 1998.

GOMES, Elizabeth. Hoje minha estreia no Open. São Paulo, 26 abr. 2018. Facebook: Elizabeth Rodrigues Gomes. Disponível em: https://www.facebook.com/elizabeth.r.gomes. Acesso em: 14 set. 2020.

HARTOG, François. Tempo, História e a escrita da História: A ordem do tempo. Revista de História, v. 1, n. 148, p.9-34, 2003.

INTERNATIONAL PARALYMPIC COMMITTEE. Explanatory guide to Paralympic classification: Paralympic summer sports [2015]. Disponível em: https://www.paralympic.org/ sites/default/files/document/150915170806821_2015_09_15+Explanatory+guide+Classification_ summer+FINAL+_5.pdf. Acesso em: 25 nov. 2017.

KÜBLER-ROSS, E. Sobre a morte e o morrer: o que os doentes terminais têm para ensinar a médicos, enfermeiras, religiosos e aos seus próprios parentes. São Paulo: Martins Fontes, 2005.

LEÃO, Lucia. Narrativas e histórias de vida na pesquisa acadêmica: reflexões sobre o método. In: RUBIO, Katia. Narrativas Biográficas: da busca à construção de um método. São Paulo: Laços, 2016. Cap. 1. p. 21-37.

LIMA, Edivaldo Pereira. Páginas Ampliadas. 4. ed. São Paulo: Manole, 2009.

MÁRQUEZ, Gabriel García. Crônica da uma morte anunciada. 42. ed. Rio de Janeiro: Record, 2011.

4 Frase de Pompeu, general romano, 106-48 a C. dita aos marinheiros, amedrontados, que recusavam viajar durante a guerra, (PLUTARCO, 2010, Tomo V). 
MINISTÉRIO DA SAÚDE. (Comp.) Esclerose Lateral Amiotrófica (ELA): o que é, causas, sintomas, tratamento, diagnóstico e prevenção. 2018. Disponível em: http://portalms. saude.gov.br/saude-de-a-z/esclerose-lateral-amiotrofica-ela. Acesso em: 04 mar. 2019.

MONTAIGNE, Michel. Os Ensaios: Livro I. 2. ed. São Paulo: Martins Fontes, 2002.

PINHEIRO, Daniel Faria de Campos et al. Valor diagnóstico da tomografia de coluna cervical em vítimas de trauma contuso. Revista do Colégio Brasileiro de Cirurgiões, v.38, n.5 p. 299-303, 2011. Disponível em: http://www.scielo.br/scielo.php?script=sci arttext\&pid=S0100-69912011000500003\&lng=pt\&nrm=iso. Acesso em: 17 abr. 2012.

PLUTARCO. Vidas paralelas: Agesilao - Pompeyo - Alejandro - Gayo Julio César. São Paulo: Lg.livro Gratis, 2010. Tomo v. Disponível em: https://livros01.livrosgratis.com.br/ bk000480.pdf . Acesso em: 11 dez. 2019.

PREFEITURA DE SANTOS (Comp.). Beth Gomes bate dois recordes mundiais. 2018. Disponível em: https://www1.santos.sp.gov.br/?q=noticia/beth-gomes-bate-dois-recordesmundiais. Acesso em: 04 mar. 2019.

RIBEIRO, Euler. Esteves. Tanatologia: vida e finitude. Rio de Janeiro: Unati, 2008.

RUBIO, Katia. $O$ atleta e o Mito do Herói: o imaginário esportivo contemporâneo. 2 ed. São Paulo, Casa do Psicólogo, 2001.

RUBIO, Katia. Preservação da Memória. São Paulo: Kepós, 2014.

SÁ, Maria de Fátima de. Direito de morrer: eutanásia, suicídio assistido. Belo Horizonte: Del Rey, 2001.

SANCHÉZ, Álvaro. Dos Jogos do Rio à eutanásia: a última disputa de Marieke Vervoort. El País, Madrid, 2016. Disponível em: https://brasil.elpais.com/brasil/2016/08/15/ deportes/1471268175 363552.html. Acesso em: 26 ago. 2020.

SANTISI, Sebastián. Poesias coligidas de Fernando Pessoa, 2003. Disponível em: http:// www.fpessoa.com.ar/poesias.asp?Poesia=036. Acesso em: 14 set. 2020.

SCHNARNDORF, Susana. Tempos difíceis. São Paulo, 27 abr. 2018. Facebook: Susana Schnarndorf. Disponível em: https://www.facebook.com/photo. php? fbid $=2104150279600430 \&$ set $=p b .100000164360303 .-2207520000 . . \&$ type $=3$. Acesso em: 14 set. 2020

TARDE, Gabriel; SIMMIAND, François. In: TARDE, Gabriel; VARGAS, Eduardo (ed.). Monadologia: Sociologia e outros ensaios. São Paulo: Cosac Naify, 2018 [1901]. n. IX, p. 103-118.

TONON, Luciane Maria Micheletti. A influência da elegibilidade na carreira do atleta paraolímpico. Olimpianos Journal Of Olympic Studies, v. 1, n. 1, p. 79-89, 2017. DOI : http://dx.doi.org/10.30937/2526-6314.v1n1.id6.

VERVOORT, Marieke. Can't forget the good memories! 18 set. 2019. Instagram: @ wielemie.marieke.vervoort. Disponível em: https://www.instagram.com/p/B3x0kvcH4ud/. Acesso em: 14 set. 2020. 
Abstract: This essay aims to understand how two Paralympic athletes with degenerative diseases - swimmer Susana Schnarndorf and Elizabeth Gomes, a practitioner of athletics - deal with the dichotomy of time provided by sport, a struggle "against" the clock to achieve high performance and "in favor" of extending one's lifetime. Paradoxically, it presents speeches of Belgian sprinter Marieke Vervoort, who preferred to give up her time in life and competition. The methodology used was biographical narrative starting from an invitation for the athletes to tell their life stories, which result from narratives - elements of subjectivity - which address the social roles of these women not only as athletes but also as human beings, as they suffer from the condition of mortality and brief finitude marked by the disease. Approximation with literary characters is metaphor for the harshness of that glimmer between finitude and eternity.

Keywords: Athletic Injuries. Disabled Persons. Chronic Disease. Para-Athletes.

Resumen: Este ensayo tiene como objetivo comprender cómo las atletas paralímpicas con enfermedades degenerativas Susana Schnarndorf, de la natación, y Elizabeth Gomes, del atletismo, enfrentan la dicotomía del tiempo que les da el deporte. Una lucha "contra" reloj para conquistar índices y "a favor" de extender el tiempo de vida. Paradójicamente, trae las palabras de la velocista belga Marieke Vervoort, que prefirió romper con el tiempo de vida y con las competencias. La metodología utilizada son las narrativas biográficas, que parten de una invitación para que las deportistas cuenten sus historias de vida. Las narrativas traen elementos de subjetividad que tratan no solo del rol social de estas mujeres como deportistas, sino como seres humanos, que sufren la condición de mortalidad y de una breve finitud, marcada por la enfermedad. El acercamiento a personajes literarios es una forma de metáfora de la dureza de ese destello tan tenue entre la finitud y la eternidad.

Palabras clave: Traumatismos en Atletas. Personas con Discapacitad. Enfermedad Crónica. Paratletas. 


\section{LICENÇA DE USO}

Este é um artigo publicado em acesso aberto (Open Access) sob a licença Creative Commons Atribuição 4.0 Internacional (CC BY 4.0), que permite uso, distribuição e reprodução em qualquer meio, desde que o trabalho original seja corretamente citado. Mais informações em: http://creativecommons.org/licenses/by/4.0

\section{CONFLITO DE INTERESSES}

Os autores declararam que não há conflito de interesses neste trabalho.

\section{CONTRIBUIÇÕES AUTORAIS}

Luciane Maria Micheletti Tonon: elaboração e pesquisa.

Katia Rubio: correção e orientação.

\section{FINANCIAMENTO}

O presente trabalho foi realizado com apoio da Coordenação de Aperfeiçoamento de Pessoal de Nível Superior -Brasil (CAPES) - Código de Financiamento 001 This study was financed in part by the Coordenação de Aperfeiçoamento de Pessoal de Nivel Superior - Brasil (CAPES) - Finance Code 001.

\section{ÉTICA EM PESQUISA}

Esse estudo faz parte da pesquisa: Olímpicos e Paralímpicos: separados por um instante, desenvolvida na Escola de Educação Física e Esportes da USP, e está vinculada à pesquisa "Memórias Olímpicas por Atletas Olímpicos Brasileiros", aprovada pelo Comitê de Ética da Escola de Educação Física da Universidade de São Paulo no processo 0052.0.342.000-09. As atletas Elizabeth Gomes e Susana Schnarndorf foram entrevistadas para a pesquisa e assinaram um termo de consentimento livre e esclarecido, autorizando o uso dos dados na pesquisa científica. A atleta Marieke concedeu entrevista coletiva para imprensa, onde estivemos presentes.

\section{USO DE IMAGENS}

As fotos são públicas no Flickr do Comitê Paralímpico Brasileiro para uso da imprensa e arquivo pessoal das atletas.

\section{COMO REFERENCIAR}

TONON, Luciane Maria Micheletti; RUBIO, Katia. Pelo tempo e contra o tempo: narrativas biográficas de atletas paralímpicas com doenças degenerativas. Movimento (Porto Alegre), v.26, p. e26093, jan./dez. 2020. Disponível em: https://seer.ufrgs.br/Movimento/article/view/100207. Acesso em: [dia] [mês abreviado]. [ano]. DOI: https://doi.org/10.22456/1982-8918.100207

\section{RESPONSABILIBADE EDITORIAL}

Alex Branco Fraga*, Elisandro Schultz Wittizorecki*, Ivone Job*, Mauro Myskiw*, Raquel da Silveira* 
*Universidade Federal do Rio Grande do Sul, Escola de Educação Física, Fisioterapia e Dança, Porto Alegre, RS, Brasil 